\title{
PENGARUH GAYA KEPEMIMPINAN DAN BUDAYA ORGANISASI TERHADAP KEPUASAN KERJA UNTUK MENINGKATKAN KINERJA KARYAWAN MATAHARI DEPARTEMENT STORE DUTA PLAZA DI DENPASAR
}

\author{
Ni Luh Kardini \\ Universitas Mahendradatta \\ Jalan Ken Arok No.10-12 Denpasar, Bali
}

\begin{abstract}
Abstrak : Kontribusi karyawan akan menjadi penting apabila dilakukan dengan tindakan efektif dan berperilaku secara benar. Tidak hanya jumlah usaha tetapi juga arah dari usaha. Sifat-sifat, upaya atau kemauan untuk bekerja serta berbagai hal yang merupakan dukungan organisasi sangat besar artinya bagi keberhasilan kinerja karyawan. Dalam penelitian ini menganalisis permasalahan yang dihadapi karyawan Matahari Departement Store Duta Plaza, sebagian mereka merasakan ada ketidakpuasan dalam bekerja sehingga hal ini berpengaruh terhadap kinerja yang kurang baik. Uji empiris dilakukan terhadap 120 karyawan guna mendapatkan data tentang gaya kepemimpinan dan budaya organisasi yang selama ini dianggap belum dapat memberikan harapan bagi karyawan. Alat analisis yang digunakan dalam penelitian ini adalah Structural Equation Model (SEM). Hasil Analisis SEM telah memenuhi kriteria indeks kelayakaan model (Goodness of Fit Index Criteria): chi square $=294,276$, probability $=0,000$, RMSEA $=0,116$, GFI $=0,776$, AGFI $=$ $0,697, \mathrm{CFI}=0,829$. Semua memenuhi kriteria, kecuali RMSEA dan AGFI adalah marginal. Hasil penelitian ini menunjukkan bahwa budaya organisasi tidak signifikan berpengaruh terhadap kepuasan kerja yang tidak signifikan terhadap kinerja, budaya organisasi tidak signifikan berpengaruh terhadap kinerja, gaya kepemimpinan tidak signifikan berpengaruh terhadap kinerja baik secara langsung maupun tak langsung melalui kepuasan kerja. Kepuasan kerja berpengaruh positif dan signifikan terhadap kinerja karyawan. Atas dasar hasil tersebut, implikasi manajerial yang dapat disarankan adalah peningkatan kepuasan kerja dan kinerja dapat dicapai dengan menciptakan dan menjaga budaya keterlibatan dalam budaya perusahaan, menerapkan gaya kepemimpinan partisipatif sejalan dengan memberikan tingkat gaji yang dirasa memuaskan bagi karyawan.
\end{abstract}

\section{Kata kunci : Gaya Kepemimpinan, Budaya Organisasi, Kepuasan Kerja dan Kinerja Karyawan.}

\begin{abstract}
Employee contributions will be important if done with effective actions and behave correctly. Not only the amount of effort but also the direction of the business. The nature, effort or willingness to work as well as the various things that constitute organizational support is very important for the success of employee performance. In this study analyze the problems faced by employees of Matahari
\end{abstract}


Department Store Duta Plaza, some of them feel there is dissatisfaction in work so that this affects the poor performance. Empirical test conducted on 120 employees to obtain data about leadership style and organizational culture that had been considered has not been able to provide hope for employees. Analyzer used in this research is Structural Equation Model (SEM). The result of SEM analysis has fulfilled the criteria of the model of Goodness of Fit Index Criteria: chi square = 294,276, probability $=0,000, R M S E A=0.116, G F I=0.776, A G F I=0.697, C F I$ $=0.829$. All meet the criteria, except RMSEA and AGFI are marginal. The results of this study indicate that organizational culture is not significant influence on job satisfaction is not significant to performance, organizational culture is not significant effect on performance, leadership style is not significant effect on performance either directly or indirectly through job satisfaction. Job satisfaction has a positive and significant effect on employee performance. On the basis of these results, the managerial implications that can be suggested are the improvement of job satisfaction and performance can be achieved by creating and maintaining a culture of involvement in corporate culture, applying participative leadership style in line with providing satisfactory salary levels for employees.

Keywords: Leadership Style, Organizational Culture, Job Satisfaction and Employee Performance. 


\section{PENDAHULUAN}

Salah satu tantangan yang dihadapi perusahaan-perusahaan retail di Indonesia adalah bagaimana menjadi market leader. Perusahaan harus mampu bersaing dengan kompetitorkompetitor yang ada. Hal ini di dukung oleh sumber daya manusia yang bermutu dengan kinerja kerja yang baik.. Kontribusi karyawan perusahaan pada suatu organisasi akan menentukan maju atau mundurnya perusahaan.

Kontribusi karyawan pada perusahaan akan menjadi penting, jika dilakukan dengan tindakan efektif dan berperilaku secara benar. Tidak hanya jumlah usaha tetapi juga arah dari usaha. Sifat-sifat yang ada pada diri karyawan, upaya atau kemauan untuk bekerja, serta berbagai hal yang merupakan dukungan dari organisasi sangat besar artinya bagi keberhasilan kinerja karyawan (Soehardi Sigit, 2001).

$\begin{array}{cr}\text { Keberhasilan } & \text { perusahaan } \\ \text { sangat dipengaruhi oleh kinerja }\end{array}$ karyawannya. Kinerja merupakan prestasi kerja, yakni perbandingan antara hasil kerja yang secara nyata dengan standar kerja yang ditetapkan (Dessler, 1992). Houran, J (dalam Manzoor, 2012) menyatakan bahwa tidak ada seorang karyawan pun yang ingin bekerja secara gratis begitu pula sebaliknya, mereka ingin apa yang mereka kerjakan sebanding dengan apa yang mereka terima. Kinerja karyawan adalah hasil kerja perseorangan dalam suatu organisasi. Kinerja merupakan bagian dari personal outcomes yang dimiliki oleh seorang karyawan (Manzoor, 2012). Dalam suatu organisasai baik pemerintahan maupun swasta, kinerja karyawan pada dasarnya tergantung pasa banyak faktor seperti penilaian kinerja, motivasi pekerja, kepuasan pekerja, konpensasi, pelatihan dan pengembangan, keamanan kerja, struktur organisasi serta budaya organisasi ( Manzoor, 2012).

Budaya organisasi (corporate culture) sering diartikan sebagai nilainilai, simbol-simbol yang dimengerti dan dipatuhi bersama, yang dimiliki suatu organisasi sehingga anggota organisasi merasa satu keluarga dan menciptakan suatu kondisi anggota organisasi tersebut merasa berbeda dengan organisasi lain (Waridin dan Masrukhin, 2006). Selanjutnya Waridin dan Masrukhin (2006) menyatakan bahwa budaya organisasi adalah suatu sitem nilai yang diperoleh dan dikembangkan oleh organisasi dan pola kebiasaan dan falsafah dasar pendirinya, yang terbentuk menjadi aturan yang digunakan sebagai pedoman dalam berfikir dan bertindak dalam mencapai tujuan organisasi. Budaya yang tumbuh menjadi kuat mampu memacu organisasi kearah perkembangan yang lebih baik (Robins, 1996). Hal ini berarti bahwa 
setiap perbaikan budaya kerja kearah yang lebih kondusif akan memberikan sumbangan yang sangat berarti bagi peningkatan kinerja karyawan.

Untuk mengelola dan mengendalikan berbagai fungsi subsistem dalam organisasi agar tetap konsisten dengan tujuan organisasi dibutuhkan seorang pemimpin karena pemimpin merupakan bagian penting dalam peningkatan kinerja para pekerja (Bass, 1994 dalam Cahyono, 2005). Disamping itu kemampuan pemimpin dalam menggerakan dan memberdayakan karyawannya akan berpengaruh terhadap kinerja karyawan. Perubahan lingkungan dan tehnologi yang cepat meningkatkan kompleksitas tantangan yang dihadapi oleh organisasi, hal ini memunculkan kebutuhan organisasi terhadap pemimpin yang dapat mengarahkan dan mengembangkan usaha-usaha bawahan dengan kekuasaan yang dimiliki untuk mencapai tujuan organisasi dalam membangun organisasi menuju high performance (Harvey dan Brown, 1996, dalam Cahyono, 2005). Perilaku pemimpin mempunyai dampak signifikan terhadap sikap, perilaku dan kinerja pegawai. Efektivitas pemimpin dipengaruhi oleh karakteristik bawahannya dan terkait dengan proses komunikasi yang terjadi antara pemimpin dan bawahan. Ketidakberhasilan pemimpin dikarenakan pemimpin tidak mampu menggerakan dan memuaskan karyawan pada suatu pekerjaan dan lingkungan tertentu. Tugas pimpinan adalah mendorong bawahan supaya memiliki kompetensi dan kesempatan berkembang dalam mengantisipasi setiap tantangan dan peluang dalam bekerja (Lodge dan Derek, 1992). Dengan gaya kepemimpinan yang mereka lakukan diharapkan mampu memberikan kepuasan karyawan bekerja serta meningkatkan kinerja kerja.

Gibson et al. (1995), mengemukakan tugas manajemen sumber daya manusia berkisar pada upaya mengelola unsur manusia dengan potensi yang dimiliki sehingga dapat diperoleh sumber daya manusia yang puas (satisfied) dan memuaskan (satisfactory) bagi organisasi. Salah satu tujuan bekerja adalah memperoleh kepuasan kerja. Kepuasan kerja berkaitan erat antara sikap pegawai terhadap berbagai faktor dalam pekerjaan, antara lain : situasi kerja, pengaruh sosial dalam kerja, imbalan dan kepemimpinan serta faktor lain (Lodge \& Derek, 1992, dalam Waridin \& Masrukhin, 2006). Orang akan merasa puas apabila tidak ada perbedaan (discrepancy) antara yang diinginkan dengan persepsinya atas kenyataan. Meskipun terdapat perbedaan akan tetapi kalau perbedaan tersebut positif maka orang atau pegawai akan merasa puas, demikian juga sebaliknya. Pegawai akan merasa 
puas bila mendapatkan sesuatu yang dibutuhkan. Makin besar kebutuhannya yang terpenuhi akan semakin puas, begitu sebaliknya.

\section{Matahari Department} Store adalah sebuah perusahaan ritel di Indonesia yang merupakan pemilik dari jaringan toserba Matahari. Saat ini, Matahari Department Store merupakan salah satu anak perusahaan dari Lippo Group. Per kuartal pertama tahun 2017, Matahari Department Store sudah mempunyai 151 gerai di lebih dari 60 kota di Indonesia dan satu gerai online MatahariStore.com.

Di Provinsi Bali, Matahari Department Store mendirikan empat cabang usahanya yaitu Matahari Department Store Duta Plaza, Matahari Department Store Kuta Square, Matahari Department Store Galeria dan Matahari Department Store Lippo Mall Kuta. Matahari Department Store Duta Plaza merupakan cabang usaha pertama yang didirikan di Provinsi Bali dan berlokasi di Kota Denpasar sedangkan Matahari Department Store Kuta Square, Matahari Department Store Galeria, dan Matahari Department Store Lippo Mall Kuta berlokasi di Kabupaten Badung.

Adanya target perusahaan untuk menjadi “market leader' maka diperlukan solusi untuk lebih meningkatkan kinerja karyawan serta kepuasan kerja dengan cara adanya gaya kepemimpinan yang sesuai dengan kebutuhan dan budaya organisasi yang sehat. Untuk itu dilakukan penelitian berjudul "Pengaruh Gaya Kepemimpinan, Budaya Organisasi terhadap Kepuasan
Kerja untuk meningkatkan Kinerja karyawan Matahari Departement Store Duta Plaza di Denpasar".

\section{METODE PENELITIAN}

Penelitian ini akan dilakukan pada Matahari Departement Store Duta Plaza di Denpasar. Desain penelitian ini dilakukan secara menyeluruh pada semua departemen yang ada dan dimulai dengan meneliti fenomena yang terjadi pada perusahaan tersebut. Penelitian ini akan melihat apakah antara variabel memiliki suatu hubungan atau tidak. Data yang dipergunakan dalam penelitian terhadap variabel gaya kepemimpinan, budaya organisasi, kepuasan kerja dan kinerja karyawan. Penelitian ini akan menggunakan metode survey dengan memberikan sampel kuesioner. Dalam Irawan (2007) disebutkan "metode survey adalah metode penelitian yang menggunakan kuesioner sebagai instrument utama untuk mengumpulkan data". Masih menurut Irawan(2007), dalam penelitian survey dengan kuesioner diperlukan responden dalam jumlah yang cukup agar validitas temuan tercapai dengan baik.

Populasi dalam penelitian ini adalah seluruh departmen karyawan Matahari Departement Store Duta Plaza di Denpasar Sampel yang akan digunakan dalam penelitian ini 
ditentukan dengan menggunakan rumus (Ferdinand, 2005):

Jumlah sampel $=$ jumlah indikator $\mathrm{x} 5$ sampai 10

Karena dalam penelitian ini terdapat 17 indikator, maka jumlah sampel yang digunakan adalah:

Sampel minimum $=$ Jumlah indikator $\mathrm{X}$ $5=17 \times 5=85$ Responden. Selanjutnya Hair, dkk dalam Ferdinand (2005) menemukan bahwa ukuran sampel sesuai untuk SEM adalah antara 100 - 200 sampel. Dengan mengacu pada pendapat Hair maka jumlah sampel yang dipakai dalam penelitian adalah total sejumlah 120 responden. Sampel dalam penelitian ini adalah semua bagian departemen yang ada pada Matahari Departement Store Duta Plaza di Denpasar. Teknik pengambilan sampel yang digunakan secara proposional random sampling.

Data primer dalam penelitian ini diperoleh dengan menggunakan kuesioner yang dipandu dengan wawancara. Kuesioner adalah sejumlah pertanyaan tertulis yang digunakan untuk memperoleh informasi dari responden. Kuesioner yang didistribusikan kepada karyawan Matahari Departement Store Duta Plaza di Denpasar berupa kuesioner tertutup, dimana kuesioner tertutup menggunakan skala Likert 1-5 dimana
1 menunjukan tingkatan sangat tidak setuju, sedang tingkatan 5 menunjukan sangat setuju.Data sekunder diperoleh dari perusahaan yang dijadikan obyek penelitian, juga dari penelitianpenelitian sebelumnya.

Analisis data dan interpretasi untuk penelitian yang ditujukan untuk menjawab pertanyaan-pertanyaan penelitian dalam rangka mengungkap fenomena sosial tertentu. Analisis data adalah proses penyederhanaan data ke dalam bentuk yang lebih mudah dibaca dan diimplementasikan. Metode yang dipilih untuk menganalisis data harus sesuai dengan pola penelitian dan variabel yang akan diteliti. Untuk menganalisis data digunakan The Structural Equation Modeling (SEM) dari paket software statistik AMOS dalam model dan pengkajian hipotesis. Model persamaan structural, Structural Equation Model (SEM) adalah sekumpulan teknik-teknik statistical yang memungkinkan pengujian sebuah rangkaian hubungan relatif "rumit" secara simultan (Ferdinand, 2000, hal:181).

Persamaan spesifikasi model pengukuran yaitu menentukan serangkaian matriks yang menunjukkan korelasi yang dihipotesiskan antar konstruk atau variabel.

1. RMSEA (The Root Mean Square Error of Approximation), yang menunjukkan goodness of fit yang 
dapat diharapkan bila model diestimasi dalam populasi (Hair et al., 1995,p:175). Nilai RMSEA yang lebih kecil atau sama dengan 0,08 merupakan indeks untuk dapat diterimanya model yang menunjukkan sebuah close fit dari model yang berdasarkan degrees of freedom (Browne \& Cudeck, 1993 dalam Ferdinand, 2003, p:53).

2. GFI (Goodness of Fit Index), adalah ukuran non statistical yang mempunyai rentang nilai antara 0 (poor fit) sampai dengan 1,0 (perfect fit). Nilai yang tinggi dalam indeks ini menunjukkan sebuah "better fit."

3. AGFI (Adjusted Goodness of Fit Index), dimana tingkat penerimaan yang direkomendasikan adalah bila AGFI mempunyai nilai sama dengan atau lebih besar dari 0,90 (Hair et al., 1995, Hulland et al., 1996 dalam Ferdinand, 2000, p:56)

4. CMIN/DF, adalah The Minimum Sample Discrepancy Function yang dibagi dengan degree of freedom. CMIN/DF tidak lain adalah statistik chi square $\mathrm{x}^{2}$ relatif. Bila nilai $\mathrm{x}^{2}$ relatif kurang dari 2.0 atau 3.0 adalah indikasi dari acceptable fit antara model dan data (Arbuckle, 1997 dalam Ferdinand, 2000, p:56).

5. TLI (Tucker Lewis Index), merupakan incremental index yang membandingkan sebuah model yang diuji terhadap sebuah baseline model, dimana nilai yang direkomendasikan sebagai acuan untuk diterimanya sebuah model adalah > 0,95 (Hair et al., 1995, p.175) dan nilai yang mendekati 1 menunjukkan a very good fit (Arbuckle, 1997 dalam Ferdinand,2000,p.57).

6. CFI (Comparative Fit Index), dimana bila mendekati 1, mengindikasi tingkat fit yang paling tinggi (Arbuckle,1997 dalam Ferdinand,2000,p.58). Nilai yang direkomendasikan adalah CFI lebih besar atau sama dengan 0,95 . Sebuah model dinyatakan layak jika masing-masing indeks tersebut mempunyai cut of value seperti ditunjukkan pada tabel dibawah ini.

Tabel

Goodness of-fit Indices

\begin{tabular}{|c|l|}
\hline Goodness of-fit index & Cut-off Value \\
\hline$c^{2}-$ Chi-square & $<$ chi square Tabel \\
\hline 1.Significance Probability & $\geq 0.05$ \\
\hline 2.RMSEA & $\leq 0.08$ \\
\hline
\end{tabular}

Ni Luh Kardini 


\begin{tabular}{|l|l|} 
3.GFI & $\geq 0.90$ \\
\hline 4.AGFI & $\geq 0.90$ \\
\hline 5.CMIN/DF & $\geq 2.00$ \\
\hline 6.TLI & $\geq 0.95$ \\
\hline 7.CFI & $\geq 0.95$ \\
\hline
\end{tabular}

Sumber: Dikembangkan untuk penelitian ini 7.

Mengintepretasikan dan memodifikasi model

Langkah terakhir dalam SEM adalah menginteprestasikan dan memodefikasi model, khususnya bagi model-model yang tidak memenuhi syarat dalam proses pengujian yang dilakukan. Setelah model diestimasi, residualnya haruslah kecil atau mendekati nol dan distribusi frekuensi dari kovarians residual harus bersifat simetrik (Tabachnick dan Fidell, 1997 dalam Ferdinand 2002).

Modifikasi model pertama kali diuji dengan menguji standardized residual yang dilakukan oleh model. Cut-off value sebesar 2,58 (Hair et al., 1995, Joreskog, 1993 dalam Ferdinand, A, 2002) dapat digunakan untuk menilai signifikan tidaknya residual yang dihasilkan oleh model. Nilai residual value yang lebih besar atau sama dengan 2,58 diinterprestasikan sebagai signifikan secara statis pada tingkat 5\%, dan residual yang signifikan ini menunjukan adanya prediction error yang substansial untuk sepasang indikator.

\section{HASIL ANALISIS DAN PEMBAHASAN}

\section{Analisa Full Model Structural Equation Modeling (SEM)}

Setelah measurement model dianalisis melalui konfirmatori faktor analisis dan dilihat bahwa masing-masing indikator dapat digunakan untuk mendefinisikan sebuah konstruk laten, maka sebuah full model SEM dapat dianalisis sebagai berikut :

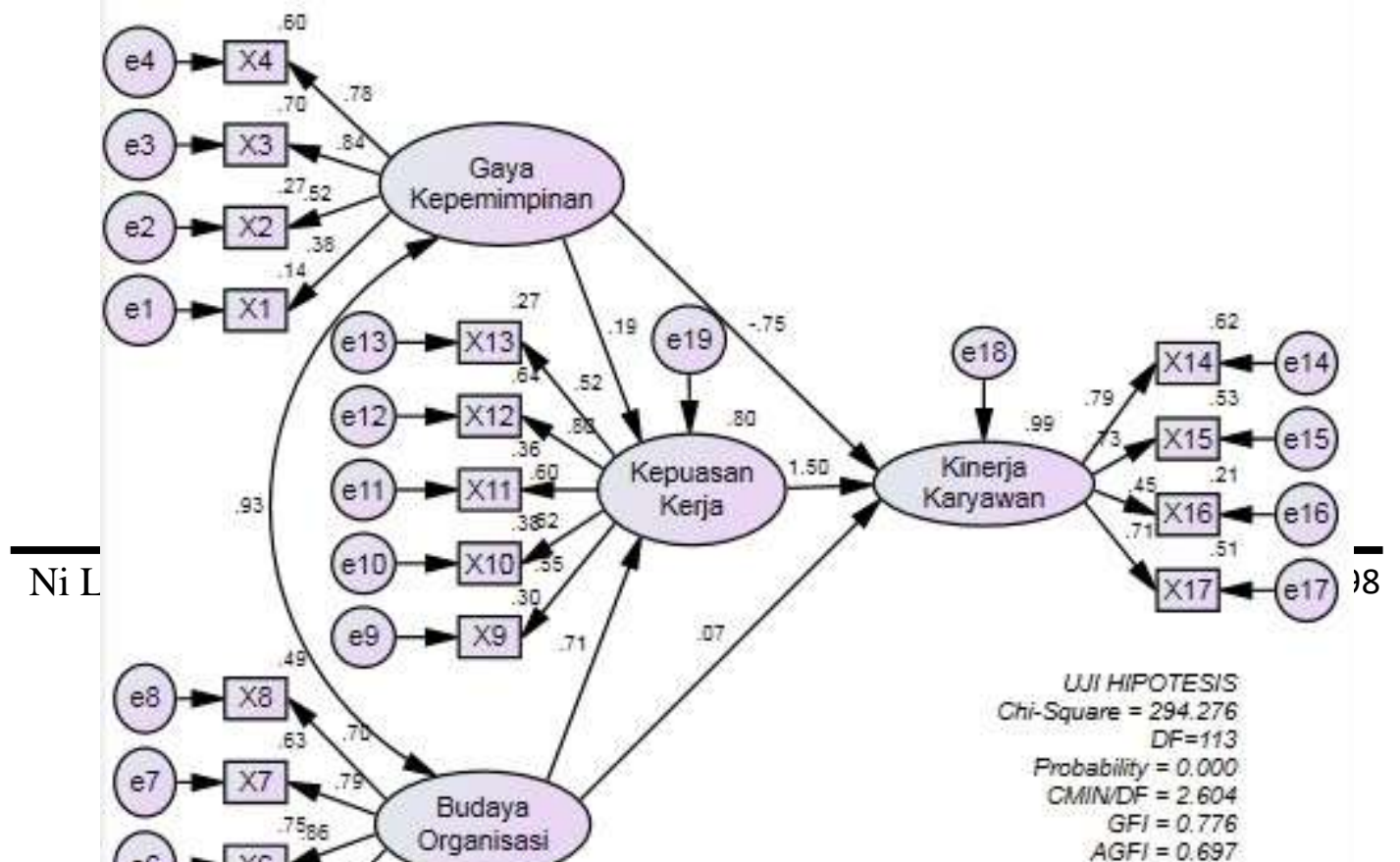


Sumber : Data Primer yang diolah, 2018

Tahap selanjutnya adalah melakukan evaluasi terhadap kesesuaian model melalui telaah berbagai kriteria goodness of fit berikut ini :

\section{Asumsi-Asumsi SEM}

a. Ukuran Sampel

Model SEM berisi empat bentuk dengan masing-masing bentuk memiliki lebih dari tiga item (variabel yang diamati), komunalitas masing-masing item yang dihasilkan > 0,6 maka dapat diestimasikan dengan sample yang mencukupi antara 100-150. Ukuran sampel yang digunakan dalam penelitian ini berjumlah 120 sehingga dapat disimpulkan bahwa model memenuhi asumsi ukuran sample.

b. Normalitas Data

Estimasi dengan Maximum Likelihood menghendaki variabel observed harus memenuhi asumsi normalitas multivariate. Analisa normalitas dilakukan dengan mengamati nilai $\mathrm{CR}$ untuk multivariate dengan rentang $\pm 2,8$ pada tingkat signifikansi $1 \%$ (Ghozali, 2004). Santoso (2018) menjelaskan bahwa sebuah distribusi dikatakan normal jika data tidak miring ke kiri atau ke kanan (disebut simetris dengan nilai skweness adalah 0), serta memiliki keruncingan adalah ideal (angka curtosis adalah 0). Akan tetapi hal ini sulit didapat, sehingga menggunakan table $\mathrm{Z}$ dengan signifikansi (1) persen dan angka $\mathrm{Z}$ adalah $\pm 2,58$. Dengan demikian, data dikatakan normal bila $\mathrm{cr}$ skweness dan cr curtosis dan angka cr multivariate berada diantara $-2,58$ sampai 2,58. Hasil pengujian normalitas menunjukkan bahwa nilai CR untuk multivariate adalah 9,174 yang berada diatas 2,58, sehingga dikatakan bahwa distribusi data variabel observed tidak normal. 


\section{Normalitas Data}

\begin{tabular}{|l|r|r|r|r|r|r|}
\hline \multicolumn{1}{|c|}{ Dariable } & min & \multicolumn{1}{c|}{$\max$} & \multicolumn{1}{c|}{ skew } & \multicolumn{1}{c|}{ c.r. } & kurtosis & \multicolumn{1}{c|}{ c.r. } \\
\hline X17 & 3 & 5 & $-0,147$ & $-0,659$ & $-0,674$ & $-1,508$ \\
\hline X16 & 1 & 5 & $-0,809$ & $-3,618$ & 1,133 & 2,533 \\
\hline X15 & 3 & 5 & $-0,197$ & $-0,880$ & $-0,805$ & $-1,801$ \\
\hline X14 & 3 & 5 & 0,028 & 0,124 & $-0,734$ & $-1,641$ \\
\hline X13 & 3 & 5 & 0,041 & 0,184 & $-0,642$ & $-1,435$ \\
\hline X12 & 3 & 5 & $-0,497$ & $-2,221$ & $-0,810$ & $-1,812$ \\
\hline X11 & 1 & 5 & $-1,082$ & $-4,838$ & 2,846 & 6,365 \\
\hline X10 & 2 & 5 & 0,101 & 0,452 & $-0,875$ & $-1,956$ \\
\hline X9 & 1 & 5 & $-0,282$ & $-1,262$ & 0,281 & 0,629 \\
\hline X8 & 1 & 5 & $-0,660$ & $-2,952$ & 0,213 & 0,477 \\
\hline X7 & 3 & 5 & $-0,732$ & $-3,273$ & $-0,529$ & $-1,183$ \\
\hline X6 & 3 & 5 & $-1,055$ & $-4,720$ & $-0,118$ & $-0,263$ \\
\hline X5 & 1 & 5 & $-1,128$ & $-5,046$ & 1,499 & 3,352 \\
\hline X4 & 2 & 5 & $-0,584$ & $-2,611$ & $-0,777$ & $-1,737$ \\
\hline X3 & 2 & 5 & $-0,721$ & $-3,225$ & $-0,210$ & $-0,471$ \\
\hline X2 & 2 & 5 & $-0,299$ & $-1,335$ & $-0,671$ & $-1,500$ \\
\hline X1 & 1 & 5 & $-0,151$ & $-0,676$ & $-0,668$ & $-1,495$ \\
\hline Multivariate & & & & & 42,572 & 9,174 \\
\hline Sumb : Da
\end{tabular}

Sumber : Data primer yang diolah, 2018.

c. Evaluasi Outliers

Deteksi terhadap multivariate outliers dilakukan dengan memperhatikan nilai mahalanno distance. Kriteria yang digunakan adalah berdasarkan nilai chi-square pada derajat kebebasan 17 yaitu jumlah variabel indikator pada tingkat signifikansi $\mathrm{p}<0,001$. Nilai mahalanno distance (17 ; 0,001) adalah sebesar 40,79. Dengan demikian, kasus ini memiliki nilai mahalanno distance lebih dari 40,79 adalah multivariate outliers.

Hasil output mahalanno distance dari analisis SEM (Lampiran 3) menunjukkan kasus nomor 106 bernilai lebih dari 40,79 sehingga terjadi multivariate outliers. Namun demikian, keseluruhan data yang digunakan dalam analisis SEM secra statistic dianggap telah memenuhi asumsi ouliers. 
Sementara, data dari kasus tersebut tetap digunakan dalam analisis dengan justifikasi mempertahankan variasi dan informasi yang diperoleh dari responden.

d. Evaluasi Multicollinearity dan Singularity

Pengujian data selanjutnya adalah untuk melihat apakah terdapat multikolinieritas dan singularitas dalam sebuah kombinasi variabel. Indikasi adanya multikolinieritas dan singularitas dapat diketahui melalui nilai determinan matriks kovarians yang benar-benar kecil atau mendekati nol. Dari hasil pengolahan data, nilai determinan matriks kovarians sample adalah:

Determinant of sample covariance matrix $=0,000$
Berdasarkan ouput analisis SEM (Lampiran 3) tidak terdeteksi adanya problem multikolinieritas dan singularitas, baik pada matrik korelasi dari variabel yang diamati (sample correlations) maupun hubungan antara variabel eksogen dan endogen. Dari evaluasi tersebut, secara statistic telah memenuhi asumsi Multicollinearity dan Singularity serta dapat digunakan untuk analisis berikutnya.

\section{Uji Kesesuaian dan Uji Statistik}

Indeks-indeks kesesuaian model yang digunakan sama seperti pada konfirmatori faktor analisis. Pengujian model SEM ditujukan untuk melihat kesesuaian model. Hasil pengolahan yang dilakukan disajikan dalam Tabel di bawah ini.

\section{Hasil Pengujian Kelayakan Model Structural Equal Model (SEM)}

\begin{tabular}{|l|c|c|l|}
\hline $\begin{array}{l}\text { Goodness of Fit } \\
\text { Indeks }\end{array}$ & Cut off Value & Hasil & Evaluasi Model \\
\hline Chi-Square (df=113) & Diharapkan Kecil & 294,276 & Baik \\
\hline Probability & $\geq 0,05$ & 0,000 & Baik \\
\hline RMSEA & $\leq 0,08$ & 0,116 & Kurang Baik \\
\hline GFI & $\geq 0,90$ & 0,776 & Baik \\
\hline AGFI & $\geq 0,90$ & 0,697 & Kurang Baik \\
\hline CMIN/DF & $\leq 2,00$ & 2,604 & Kurang Baik \\
\hline CFI & $\geq 0,95$ & 0,829 & Baik \\
\hline
\end{tabular}

Sumber: Data primer yang diolah, 2018 
Berdasarkan hasil yang disajikan dalam Tabel 6.20 terlihat bahwa nilai Chi Square $=294,276$ dengan probabilitas $=0,000$. Hal ini menunjukkan bahwa hipotesa nol yang menyatakan bahwa tidak terdapat perbedaan antara matriks

\section{Uji Kausalitas}

Setelah melakukan penilaian terhadap asumsi-asumsi yang ada pada SEM, selanjutnya akan dilakukan pengujian hipotesis. kovarians sampel dan matriks kovarians populasi yang diestimasi tidak dapat ditolak. Selain itu indeks kelayakan yang lain juga berada dalam rentang nilai yang diharapkan sehingga model ini dapat diterima.

Pengujian kelima hipotesis yang diajukan dalam penelitian ini dilakukan berdasarkan nilai Critical Ratio (CR) dari suatu hubungan kausalitas.

\section{Pengujian Hipotesis}

\begin{tabular}{|l|l|l|c|c|c|c|c|}
\hline \multicolumn{2}{|l}{} & $\begin{array}{c}\text { Std } \\
\text { Est }\end{array}$ & Est & SE & CR & P \\
\hline $\begin{array}{l}\text { Kepuasan } \\
\text { Kerja }\end{array}$ & $\begin{array}{l}\text { Gaya } \\
\text { Kepemimpinan }\end{array}$ & 0,192 & 0,241 & 0,492 & 0,489 & 0,625 \\
\hline $\begin{array}{l}\text { Kepuasan } \\
\text { Kerja }\end{array}$ & & $\begin{array}{l}\text { Budaya } \\
\text { Organisasi }\end{array}$ & 0,711 & 0,498 & 0,277 & 1,798 & 0,072 \\
\hline $\begin{array}{l}\text { Kinerja } \\
\text { Karyawan }\end{array}$ & & $\begin{array}{l}\text { Kepuasan } \\
\text { Kerja }\end{array}$ & 1,496 & 1,863 & 0,599 & 3,110 & 0,002 \\
\hline $\begin{array}{l}\text { Kinerja } \\
\text { Karyawan }\end{array}$ & $\begin{array}{l}\text { Gaya } \\
\text { Kepemimpinan }\end{array}$ & $(0,745)$ & $(1,160)$ & 0,900 & $(1,289)$ & 0,197 \\
\hline $\begin{array}{l}\text { Kinerja } \\
\text { Karyawan }\end{array}$ & $\begin{array}{l}\text { Budaya } \\
\text { Organisasi }\end{array}$ & 0,074 & 0,064 & 0,504 & 0,128 & 0,898 \\
\hline
\end{tabular}

Sumber: Data primer yang diolah, 2018

\section{Pengujian Hipotesis}

\section{a. Pengujian Hipotesis Pertama}

Parameter estimasi untuk pengujian pengaruh gaya kepemimpinan terhadap kepuasan kerja menunjukkan nilai CR sebesar 0,489 dengan probabilitas sebesar 0,625 . Oleh karena nilai probabilitas < 0,05 maka dapat disimpulkan bahwa variabel gaya kepemimpinan tidak berpengaruh terhadap kepuasan kerja.

\section{b. Pengujian Hipotesis Kedua}

Parameter estimasi untuk pengujian pengaruh budaya organisasi terhadap kepuasan kerja menunjukkan nilai CR sebesar 1,798 dengan probabilitas sebesar 0,072. Oleh karena nilai probabilitas $<0,05$ maka dapat disimpulkan bahwa variabel budaya organisasi tidak berpengaruh terhadap kepuasan kerja.

\section{c. Pengujian Hipotesis Ketiga}


Parameter estimasi untuk terhadap kinerja karyawan pengujian pengaruh kepuasan kerja menunjukkan nilai CR sebesar 0,128 terhadap kinerja karyawan menunjukkan nilai CR sebesar $-1,289$ dengan probabilitas sebesar 0,002 . Oleh karena nilai probabilitas $<0,05$ maka dapat disimpulkan bahwa variabel kepuasan kerja berpengaruh terhadap kinerja karyawan.

\section{d. Pengujian Hipotesis Keempat}

Parameter estimasi untuk pengujian pengaruh gaya kepemimpinan terhadap kinerja karyawan menunjukkan nilai CR sebesar -1,359 dengan probabilitas sebesar 0,174. Oleh karena nilai probabilitas < 0,05 maka dapat disimpulkan bahwa variabel gaya kepemimpinan tidak berpengaruh terhadap kinerja karyawan.

\section{e. Pengujian Hipotesis Kelima}

Parameter estimasi untuk dengan probabilitas sebesar 0,898 . Oleh karena nilai probabilitas $<0,05$ maka dapat disimpulkan bahwa variabel gaya kepemimpinan tidak berpengaruh terhadap kinerja karyawan.

\section{Analisa Pengaruh}

Analisa pengaruh dilakukan untuk menganalisis kekuatan pengaruh antar konstruk baik pengaruh yang langsung, tidak langsung, dan pengaruh totalnya. Efek langsung (direct effect) tidak lain adalah koefisien dari semua garis koefisien dengan anak panah satu ujung. Efek tidak langsung (indirect effect) adalah efek yang muncul melalui sebuah variabel antara. Efek total (total effect) adalah efek dari berbagai hubungan (Ferdinand, 2005, p.296).

pengujian pengaruh budaya organisasi

Gambar 6.12

\section{Pengaruh Antar Variabel Dalam Diagram Jalur}

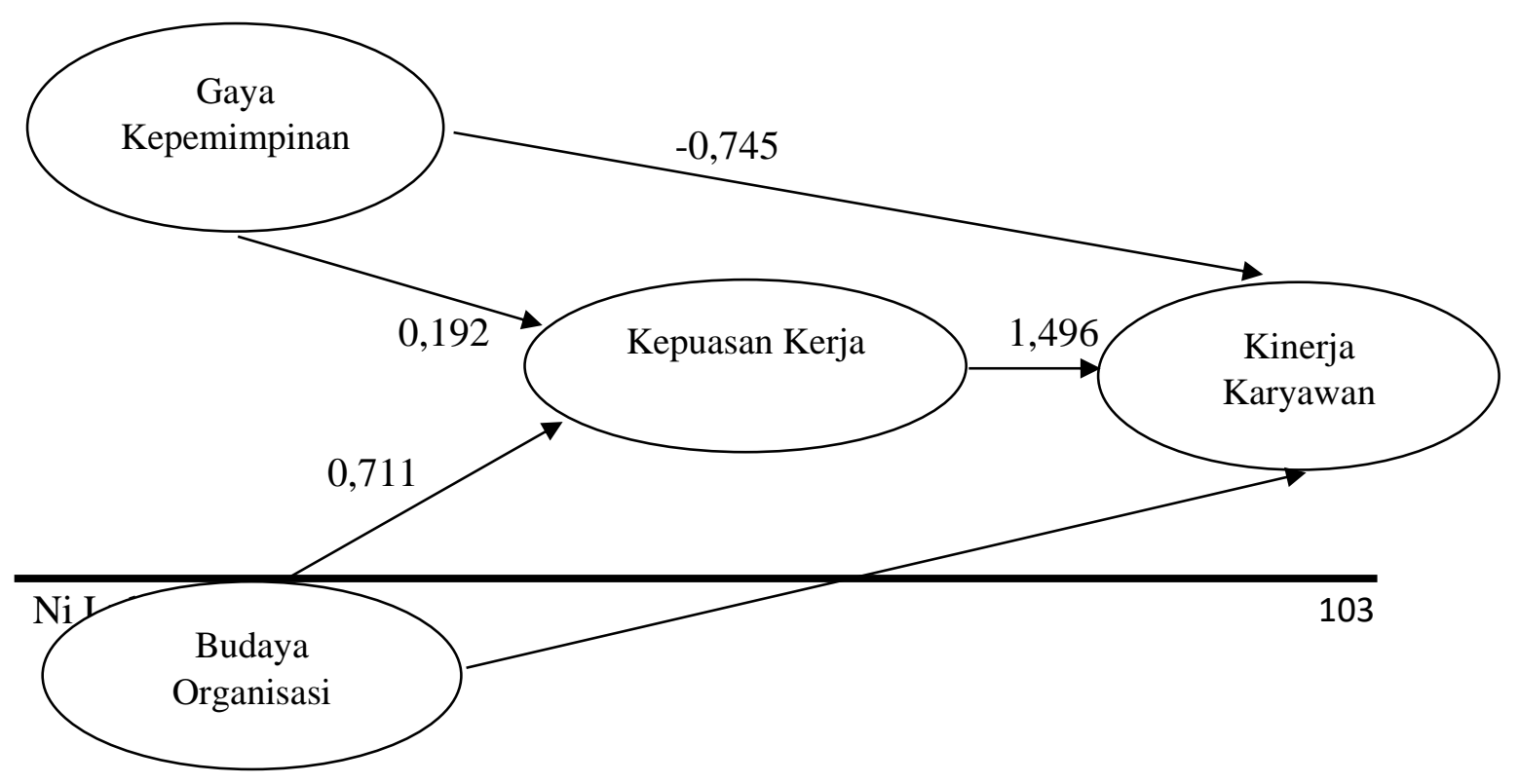


0,074

Sumber : Dikembangkan dalam penelitian ini

Pengujian Pengaruh Variabel Intervening

\begin{tabular}{|c|c|c|}
\hline & $\begin{array}{l}\text { Gaya Kepemimpinan - } \\
\text { Kinerja Kerja }\end{array}$ & $\begin{array}{l}\text { Budaya Organisasi - } \\
\text { Kinerja Kerja }\end{array}$ \\
\hline Pengaruh Langsung & $=-0,745$ & $=0,074$ \\
\hline Pengaruh Tidak Langsung & $\begin{array}{l}=0,192 \times 1,496 \\
=0,287\end{array}$ & $\begin{array}{l}=0,711 \times 1,496 \\
=1,064\end{array}$ \\
\hline Pengaruh Total & $\begin{array}{l}=-0,745+0,287 \\
=-0,458\end{array}$ & $\begin{array}{l}=0,074+1,064 \\
=1,138\end{array}$ \\
\hline Kesimpulan & $\begin{array}{l}\text { Pengaruh Total > Pengaruh } \\
\text { Langsung : intervening perlu }\end{array}$ & $\begin{array}{l}\text { Pengaruh Total > Pengaruh } \\
\text { Langsung : intervening perlu }\end{array}$ \\
\hline
\end{tabular}

Sumber : Data primer yang diolah, 2018

Dari informasi informasi yang disajikan dalam diketahui bahwa pengaruh gaya kepemimpinan dan budaya organisasi terhadap kinerja karyawan masing-masing memiliki pengaruh total yang lebih besar dari pengaruh langsung, artinya kepuasan karyawan memiliki peran yang penting dalam memediasi pengaruh gaya kepemimpinan dan budaya organisasi terhadap kinerja karyawan Matahari Departement Store Duta Plaza di Denpasar

\section{Menarik kesimpulan telah} disampaikan mengenai proses analisis data dan pengujian terhadap kelima hipotesis yang diajukan sesuai dengn justifikasi teoritis yang telah diuraikan pada sebelumnya. Dimana model yang diajukan telah dilakukan uji kesesuaian model dengan menggunakan pendekatan kriteria goodness of fit dan didapatkan hasil yang baik.

\section{Kesimpulan Hasil Pengujian Hipotesis Penelitian}

\begin{tabular}{|c|l|c|}
\hline & \multicolumn{1}{|c|}{ Hipotesis } & Kesimpulan \\
\hline $\mathrm{H}_{1}$ & $\begin{array}{l}\text { Gaya kepemimpinan berpengaruh positif terhadap } \\
\text { kepuasan kerja }\end{array}$ & ditolak \\
\hline
\end{tabular}




\begin{tabular}{|c|l|c|}
$\mathrm{H}_{2}$ & $\begin{array}{l}\text { Budaya Organisasi berpengaruh positif terhadap } \\
\text { kepuasan kerja }\end{array}$ & ditolak \\
\hline $\mathrm{H}_{3}$ & $\begin{array}{l}\text { Kepuasan kerja berpengaruh positif terhadap kinerja } \\
\text { karyawan }\end{array}$ & diterima \\
\hline $\mathrm{H}_{4}$ & $\begin{array}{l}\text { Gaya kepemimpinan berpengaruh positif terhadap } \\
\text { kinerja karyawan }\end{array}$ & ditolak \\
\hline $\mathrm{H}_{5}$ & $\begin{array}{l}\text { Budaya Organisasi berpengaruh positif terhadap } \\
\text { kinerja karyawan }\end{array}$ & ditolak \\
\hline
\end{tabular}

Sumber: Data primer yang diolah, 2008 
Jurnal Satyagraha, Vol. 02, No. 02, Agustus 2019 - Januari 2020 ISSN :2620-6358

Berdasarkan tabel diatas menunjukkan bahwa dari kelima hipotesis yang diuji dalam penelitian ini semua hipotesis dapat dibuktikan dan diterima secara statistik.

\subsection{Pembahasan}

Perusahaan sangat dipengaruhi oleh kinerja karyawannya. Perusahaan mengusahakan berbagai strategi untuk meningkatkan karyawannya. Salah satu usaha yang dapat dilakukan adalah dengan memberikan kepuasan kerja bagi karyawannya. Kepuasan kerja ini tidak lepas dari elemen perusahaan seperti budaya organisasi dan gaya kepemimpinan yang diterapkan. Hal tersebut karena karyawan selalu berinteraksi dengan karyawan yang lain dimana karakteristik masing-masing karyawan tersebut dapat membentuk atau terpengaruh budaya organisasi serta gaya kepemimpinan. Penelitian ini menganalisis faktor-faktor yang berkaitan dengan Kepuasan Kerja yang mempengaruhi Kinerja Karyawan di Matahari Departement Store Duta Plaza di Denpasar. Variabel-variabel yang mendukung penelitian ini diambil dari beberapa jurnal penelitian, antara lain: Kirk L Rongga (2001), Narhajati Ma'num dan Bisma Dewabrata (1995), Wallace (1983), JN Hood (1992), Glisson dan Durick (1988), De Groot et. al. (2000), Church (1997), Robbin (2006). Waridin dan Masrukhin (2006), Denison (1990),
Lodge dan Derek (1993), House (1998), Waridin dan Guritno (2006), Bass (1994), Ostroff (1992). Berdasarkan telaah pustaka dikembangkan 5 hipotesa yaitu: (1) Gaya Kepemimpinan tidak berpengaruh positif terhadap Kepuasan Kerja (2) Budaya Organisasi berpengaruh tidak positif terhadap Kepuasan Kerja (3) Kepuasan Kerja berpengaruh positif terhadap Kinerja Karyawan (4) Gaya Kepemimpinan tidak berpengaruh positif terhadap Kinerja Karyawan (5) Budaya Organisasi tidak berpengaruh positif terhadap Kinerja Karyawan dan. Hasil penelitian ini diharapkan dapat menjawab rumusan masalah penelitian yaitu bagaimana meningkatkan kinerja karyawan melalui budaya organisasi, gaya kepemimpinan dan kepuasan kerja..

Dalam penelitian ini data primer diperoleh secara langsung dari responden melalui penyebaran kuesioner pada karyawan Matahari Departement Store Duta Plaza di Denpasar. Kuesioner ini terdiri dari pertanyaan tertutup dan pertanyaan terbuka. Teknik pengambilan sampel diambil secara proporsional.

Jumlah responden yang digunakan dalam penelitian ini adalah 120 orang yang merupakan karyawan Matahari Departement Store Duta Plaza di Denpasar. Teknik analisis yang digunakan adalah Structural Equation Modeling. Hasil analisis data yang diperoleh akan menjelaskan hubungan kausalitas antara 
Jurnal Satyagraha, Vol. 02, No. 02, Agustus 2019 - Januari 2020 ISSN :2620-6358

variabel yang dikembangkan dalam penelitian ini.

Pengukuran konstruk eksogen dan endogen telah diuji dengan menggunakan analisis konfirmatori. Selanjutnya kedua model pengukuran tersebut dianalisis dengan Structural Equation Modeling untuk menguji hubungan kausalitas antara variabel yang mempengaruhi dan dipengaruhi oleh inovasi produk dan yang mempengaruhi kinerja pemasaran memenuhi kriteria goodness of fit yaitu Chi-Squares $=294,276$, probability $=$ $0,000, \mathrm{CMIN} / \mathrm{DF}=2,604, \mathrm{GFI}=0,776$, AGFI $=0,697$, RMSEA $=0,116$ dan CFI $=0,829$.

Dari Hasil pengolahan data diperoleh nilai Critical Ratio (CR) pada nilai Critical Ratio (CR) hubungan variabel Gaya Kepemimpinan dan Kepuasan Kerja sebesar 0,489 dengan probabilitas 0,625, hubungan antara variabel Budaya Organisasi dengan variabel Kepuasan Kerja sebesar 1,798 dengan probabilitas sebesar 0,072 , nilai Critical Ratio (CR) hubungan variabel Kepuasan Kerja dan variabel Kinerja Karyawan adalah 3,110 dengan probabilitas sebesar 0,002, nilai Critical Ratio (CR) hubungan variabel Gaya Kepemimpinan dan Kepuasan kerja sebesar -1,289 dengan probabilitas 0.197 dan nilai Critical Ratio (CR) hubungan variabel Budaya Organisasi dan Kinerja
Karyawan sebesar 0,128 dengan probabilitas 0,898 .

Setelah dilakukan penelitian yang menguji lima hipotesa yang terdapat dalam penelitian ini, maka dapat diambil kesimpulan dari hipotesis-hipotesis tersebut. Kepuasan Kerja berpengaruh positif terhadap Kinerja Karyawan.

Hasil penelitian ini menunjukan bahwa hipotesa yang berbunyi 'Kepuasan Kerja berpengaruh positif terhadapa Kinerja Karyawan' dapat diterima. Dengan demikian penelitian ini mendukung penelitian Ostroff (1992) dan Robin(1996). Indikator-indikator dalam variabel ini telah disesuaikan dengan kondisi karyawan Matahari Departement Store Duta Plaza di Denpasar. Karyawan yang merasakan kepuasan dari pekerjaannya akan berkinerja lebih baik. Hal tersebut ditandai dengan pencapaian standar profesional, kualitas kerja yang lebih tinggi, kuantitas kerja yang lebih besar dan munculnya kreatifitas-kreatifitas karyawan. Dari hasil penelitian diketahui bahwa agar kinerja karyawan tinggi, Kepuasan Kerja yang tinggi perlu dicapai.

\section{SIMPULAN DAN SARAN}

\section{Simpulan}

Penelitian ini merupakan usaha menjawab masalah penelitian, dimana pada bab I disebutkan bahwa masalah penelitian ini adalah bagaimana meningkatkan 
Jurnal Satyagraha, Vol. 02, No. 02, Agustus 2019 - Januari 2020 ISSN :2620-6358

kepuasan kerja yang dapat mempengaruhi Kinerja Karyawan Matahari Departement Store Duta Plaza di Denpasar. Untuk menjawab masalah penelitian tersebut, karyawan medis dan non medis diambil sebagai responden. Kuesioner telah dibentuk untuk mengetahui bagaiaman kinerja dan kepuasan kerja karyawan. Dari Hasil analisis penelitian didapatkan bahwa Kepuasan Kerja dapat dicapai melalui Gaya Kepemimpinan yang tepat dan Budaya Organisasi yang mendukung. Dengan demikian Kinerja Karyawan akan lebih tinggi.

Gaya Kepemimpinan partisipatif merupakan variabel penting untuk meningkatkan Kepuasan Kerja agar dapat meningkatkan Kinerja Karyawan. Dari hasil analis diketahui bahwa komponen Gaya Kepemimpinan yang partisipatif merupakan komponen yang lebih berpengaruh dibandingkan komponen gaya pengasuh, gaya otoriter dan gaya berorientasi pada tugas. Gaya Kepemimpinan yang partisipatif akan meningkatkan kepuasan dengan penyelia dan kepuasan dengan pekerjaan itu sendiri, dengan demikian standar profesionalisme sebagai salah satu ukuran kinerja karyawan akan dapat dicapai.

Budaya Organisasi terbukti merupakan faktor yang mampu meningkatkan Kepuasan Kerja. Dari hasil analisa, komponen Budaya Organisasi yang paling menentukan adalah pelibatan. Dari hasil tersebut maka perusahaan sebaiknya meningkatkan pelibatan karyawan.

\subsection{Saran}

Penelitian ini akan dilakukan pada Matahari Departement Store Duta Plaza, berdasarkan bukti empiris yang diperoleh dengan sejumlah keterbatasan yang tidak dapat dihidari dari penelitian ini, selanjutnya dapat disarankan untuk sumber penelitian dimasa mendatang dapat mengikutkan variabel-variabel lainnya. Untuk emiten, gaya kepemimpinan dapat lebih mempengaruhi bawahan sehingga tujuan perusahaan yang diharapkan untuk mencapai output yang dihasilkan dari karyawan akan semakin maksimal.

\section{DAFTAR PUSTAKA}

Bass, B.M. \& Avolio, B.J. 1994. "Improving Organizational Effectiveness: Through Transformational Leadership". London: Sagc Publications, Inc.

Cahyono, Suharto, 2005, "Pengaruh Budaya Organisasi, Kepemimpinan Dan Motivasi Kerja Terhadap Kinerja Sumberdaya Manusia Di Sekretariat DPRD Propinsi Jawa Tengah, JRBI, Vol.1..

Dessler, G, 1992, "Manajemen Personalia", Penerbit Erlangga, Jakarta. 
Jurnal Satyagraha, Vol. 02, No. 02, Agustus 2019 - Januari 2020 ISSN :2620-6358

Dessler, Garry, 1992, “Manajemen Sumber Daya Manusia", PT Prenhalindo, Jakarta.

Ferdinand, Augusty, 2006, "Metode Penelitian Manajemen : Pedoman Penelitian Untuk Penulisan Skripsi, Tesis, dan Disertasi Ilmu Manajemen", BP Undip, Semarang.

Ferdinand, Augusty, 2006, "Structural Equation Modeling : Dalam Penelitian Manajemen”, BP Undip, Semarang.

Ghozali, Imam, 2008, “Konsep dan Aplikasi Dengan Program AMOS 16.0”, BP Undip, Semarang.

Gibson et al., 1995, "Organisasi : Perilaku, Struktur, Proses". Edisi kelima, Jilid 1, Cetakan 8, Jakarta: Penerbit Erlangga

Guritno, Waridin, 2005, "Pengaruh Persepsi Karywan Mengenai Perilaku Kepemimpinan Kepuasan Kerja Dan Motivasi Terhadap Kinerja", JRBI, Vol.1.

Lodge B. dan C. Derek, 1993, "Organizational Behavior and Design". Terjemahan Sularno Tjiptowardoyo, Gramedia, Jakarta.

Manzoor, Q, 2012, “Impact of Employees Motivation on Organizational Effectiveness. Business Manajement and strategy". Vol. 3(1), pp. 1-12.
Soehardi Sigit, 2001, "Esensi Teori Perilaku Organisasional”, Fakultas Ekonomi Universitas Sarjana Wiyata Taman Siswa, Yogyakarta.

Waridin dan Masrukhin, 2006, "Pengaruh Motivasi Kerja, Kepuasan Kerja, Bidaya Organisasi, dan Kepemimpinan Terhadap Kinerja Pegawai", Ekobis, Vol.7, No.2. 